\title{
A Teoria dos Blocos Semânticos e as significações de entremeio: um estudo sobre os quase-blocos
}

\author{
Julio Cesar Machado*
}

\section{Resumo}

Este artigo tem por objetivo geral refletir sobre a nova noção de quase-bloco, proposta por Carel e Ducrot nos anos de 2013-2014 em Paris, na França, para pensar significações limítrofes e intermediárias na língua. O corpus, de natureza teórica e semântica, constitui-se por um conjunto de quatro significações oriundas da expressão "vida biológica humana": óbito, vida, morte parcial e morte emocional. Dito tecnicamente, trata-se do bloco semântico de vida biológica, composto inicialmente de quatro aspectos principais. Os resultados orientam para a direção teórica de flagrar o fenômeno de um paradoxo semântico nesse corpus, dado pela investigação da expressão "morto-vivo", ali. Tecnicamente, os quatro aspectos de um bloco preveem quatro relações novatas, chamadas de quase-blocos transpostos e quase-blocos conversos, e o resultado principal desta pesquisa é o fenômeno flagrado de um novo quase-bloco, chamado recíproco. Nesse quadro, os objetivos específicos são: (i) pensar as noções teóricas clássicas da Teoria dos Blocos Semânticos, ini- cialmente, o que possibilitará (ii) melhor compreender o engendramento teórico de dois tipos de quase-blocos propostos pelos autores: o quase-bloco converso e o quase-bloco transposto; por fim, (iii) analisar a hipótese: a comprovação de um novo quase-bloco ainda não trabalhado pelos autores: o quase-bloco recíproco, reclamado a partir do problema da expressão morto-vivo, que ilustra semantismos paradoxais.

Palavras-chave: Argumentação. Blocos semânticos. Quase-bloco. Paradoxo.

\footnotetext{
Doutor em Estudos da Linguagem - Linguística pela Universidade Federal de São Carlos (2015) e pela École des Hautes Études en Sciences Sociales de Paris, França (2013-2014). Coordenador do Grupo de Investigações Semânticas e Discursivas - GISD-CNPq. E-mail: julio. semantica@gmail.com
}

\footnotetext{
Data de submissão: fev. 2017 - Data de aceite: mar. 2017 http://dx.doi.org/10.5335/rdes.v13i1.6715
} 


\section{Introdução e metodologia: TBS, uma teoria em construção}

Este artigo é de cunho teórico. E falar teoricamente da Teoria dos Blocos Semânticos (TBS) é entender, sobretudo, pensamos, uma teoria ainda em construção, muito embora já rigorosamente engendrada. A TBS é uma teoria inacabada, está ainda (e sempre) em período de metarreflexão, o que conclama estudos teóricos que a façam progredir.

No interior deste quadro de uma teoria em construção, propomos a temática de um estudo ampliativo das noções de blocos semânticos, na esteira de estudos de seus fundadores: Dra. Marion Carel e Dr. Oswald Ducrot. Nessa linha de preocupação, este artigo elege a seguinte questão-problema, de caráter semântico:

\ como pensar, no conjunto de significâncias que constituem a expressão vida biológica (principalmente as estruturais: vida, morte, morte parcial e morte emocional), expressões de tipo paradoxal como morto-vivo?

Para esta investigação, elaboramos uma hipótese teórica: a proposta de um novo quase-bloco. Metodologicamente, valer-nos-emos de um corpus simples: a palavra composta morto-vivo, fora de qualquer uso. Para investigar nossa hipótese, definimos três objetivos neste trabalho: (i) apresentação do arcabouço teórico da TBS, enquanto revisão para operar com maior rigor nossa proposta teórica; (ii) apresentação e aprofundamento da nova noção de quase-bloco, nossa noção em foco, recém-proposta; e, finalmente, (iii) a análise e averiguação da nossa hipótese de um quase-bloco recíproco no interior da disposição teórica da TBS.

\section{Fundamentação teórica: o aspecto argumentativo e interdependência}

Com o abandono da teoria dos topoï, Ducrot assume que Carel devolveu e aprofundou a coerência saussureana aos trabalhos sobre argumentação na língua, de tal modo que a significação e o sentido não são mais constituídos por crenças ou ideias psicológicas (dos topoï), mas são perceptíveis senão na língua e no discurso (DUCROT, 2009, p. 22). Preferindo uma total fidelidade ao propósito saussureano de estudar a língua por ela mesma ou, como prefere Ducrot, sobre a égide de uma "concepção estrutural da enunciação" (DUCROT, 1984, p. 89), a argumentação agora é ilustrada metodológica e procedimentalmente através do aspecto argumentativo: duas entidades (A, B) interligadas por um conector (CONN). Tecnicamente, o aspecto argumentativo é representado por "A CONN B", em que o conector será sempre "portanto" ou "no entanto". Por exemplo, dado os dois enunciados (DUCROT, 2009, p. 22): 
I) (a) Tu diriges depressa demais,

(b) tu corres o risco de sofrer um acidente.

II) (a) Tu diriges depressa demais, (b') tu corres o risco de cometer uma infração.

Observa-se que, em ambos os enunciados, (a) está encadeado a (b). Segundo Carel e Ducrot (2008, p. 9), o (a) leva o nome de suporte ou antecedente, e o (b) de aporte ou consequente. No que tange aos exemplos, vemos que em (I) o suporte "tu diriges depressa demais" está encadeado ao aporte "tu corres o risco de sofrer um acidente". E que em (II) o mesmo suporte (a) está encadeado a um outro suporte (b') "tu corres o risco de cometer uma infração".

Isso mostra que temos dois sentidos distintos para a expressão "depressa demais", construídos discursivamente (funcionalmente, neste contexto específico). Pela metodologia da TBS, o processo de análise do enunciado se dará pela paráfrase em "portanto", que terá como aspecto:

I') [Depressa demais portanto correr o risco de sofrer um acidente].

II') [Depressa demais portanto cometer uma infração].

Ao dado "expressão conectivo expressão", ou, tecnicamente, [X CONN Y], dá-se o nome de aspecto argumentativo. Agora, suponha-se que fosse o caso que ambos os motoristas não fossem prudentes, que se tratassem de aventureiros inveterados, e redarguiram aos seus caronas:

I") Relaxa, mesmo que eu corra eu não chego em casa todos os dias?

II")Relaxa, eu conheço todos os pontos de radar dessa região.

Percebemos que ambas, (I") e (II"), são respostas aos enunciados (I) e (II) e, por isso, não podemos lê-los separadamente (toda resposta pressupõe uma pergunta, senão não seria resposta). $\mathrm{O}$ que se passa é que nos enunciados finais há uma concordância com a significação "perigoso" da estrutura "depressa demais", mas mesmo assim transgride-se essa concordância. Isso se chama transgressão, e é tratada pela TBS pelo aspecto do tipo "no entanto" (em que NEG significa “negação"):

I"') [Depressa demais no entanto NEG- correr o risco de sofrer um acidente].

II"') [Depressa demais no entanto NEG- cometer uma infração].

Como vimos, em suma, a ideia básica da TBS ou, segundo Carel, a grande hipótese ou o "lema da TBS" (CAREL; DUCROT, 2014b, p. 78) que todo enunciado é parafraseável por um encadeamento do tipo normativo (portanto) ou do tipo transgressivo (no entanto). Tanto Ducrot como Carel postulam que “os encadeamentos argumentativos estão na base de todas as construções semânticas" (CAREL, 2013, p. 3). 
Formalmente, o signo, enquanto unidade menor de um dispositivo teórico-semântico, no caso da TBS, será a relação inseparável: [X CONN Y] (DUCROT, 2002, p. 9), em que o $X$ se chamará suporte ou antecedente e o Y, aporte ou consequente (CAREL; DUCROT, 2008, p. 9-10); por exemplo, a interdependência entre o suporte "uniforme" e o aporte "enfadonho", que, se compreendidos em conjunto, ilustrará a argumentação de monótono, seu aspecto: [UNIFORME PORTANTO ENFADONHO] (CAREL, 2012, p. 44).

Ou seja: o que é a argumentação para essa teoria? A argumentação (significação ou sentido) é a inseparabilidade entre duas palavras ou expressões unidas por um conector, isto é, a interdependência; ou, mais tecnicamente: o aspecto argumentativo é a interdependência entre um suporte e um aporte unidos por um conector do tipo "portanto" ou "no entanto".

Por exemplo, não se pode falar, no caso citado, que o sentido de (I) seja [depressa demais] + [sofrer acidente]. Ao contrário, o sentido é: [depressa demais + sofrer acidente]. A constitutividade de inseparabilidade entre duas entidades, suporte (ou antecedente) mais aporte (ou consequente), é assim descrita por Ducrot: “[...] a própria palavra demais presente no antecedente, só pode ser compreendida em relação ao consequente" (DUCROT, 2009, p. 22). Não há como negar que "risco de sofrer acidente" está inscrito na expressão “depressa demais". Isto é: se alguém na situação de dirigir enuncia "depressa demais", não importa o que se queira ao enunciar isso, não é possível fugir do sentido de "risco de sofrer acidente". Isso é a interdependência semântica: a impossibilidade de seccionar os sentidos globais de [depressa-demais-portanto-risco-de-sofrer-um-acidente].

A base da significação está na seguinte interdependência: toda palavra ou enunciado reclamará um suporte mais um aporte que lhe explique. A interdependência de ambos, através de um conector ("portanto" ou "no entanto"), será a descrição da significação, a argumentação ou, tecnicamente, o aspecto argumentativo: [suporte CONN aporte]. Como conclui Ducrot, corrigindo-se de posturas anteriores: "Não há, pois, propriamente falando, passagem de $\mathrm{A}$ a $\mathrm{C}$, não há justificação de $\mathrm{C}$ para um enunciado A que seria compreensível em si mesmo [...] O encadeamento apresenta portanto $C$ como já incluído no termo A" (DUCROT, 2009, p. 22).

Há ainda uma noção cara à TBS: $o$ valor. Epistemologicamente, há uma singularidade metodológica que particulariza toda a TBS: a argumentação, noção pela qual a TBS investiga a significação e o sentido, e que será tecnicamente tratada sempre pelo valor (da frase ou do enunciado). Esse valor preserva o propósito da TBS de observar nas frases as marcas relativas à sua construção, $\mathrm{e}$ no enunciado as marcas relativas à sua 
enunciação (DUCROT, 1984). E o fará pela dinâmica de duas noções:

Os dois valores que a TBS associará a um enunciado serão o aspecto que ele exprime e o encadeamento que lhe parafraseia" (CAREL, 2011, p. 160, grifo nosso).

Em consonância com Ducrot, quando afirma que o enunciado tem por função ilustrar um retrato da enunciação (DUCROT, 1984), Carel está dizendo que uma frase/enunciado tem por função semântica ilustrar aspectos, concretizando-os (CAREL, 2011, p. 161). Assim, a TBS marca o movimento semântico do enunciado à frase, ou tecnicamente, a noção de aspecto marca um movimento do sentido (particular, do enunciado) à significação (universal, da frase). Para Carel, o aspecto tem uma característica universal que o determina. Observemos o Quadro 1:

Quadro 1 - O valor de uma frase ou enunciado

\begin{tabular}{|l|l|}
\hline \multicolumn{2}{|c|}{ Valor de uma frase ou enunciado } \\
\hline \multicolumn{1}{|c|}{ Aspecto } & \multicolumn{1}{c|}{ Encadeamento } \\
\hline $\begin{array}{l}\text { Expresso pela frase ou enunciação } \\
\text { O propósito da frase ou do enunciado } \\
\text { É universal (divide um universal com outros) }\end{array}$ & $\begin{array}{l}\text { Evocado pelo aspecto (ilustra um aspecto) } \\
\text { Concretiza aspectos (parafraseia aspectos) } \\
\text { É singular (distingue-o dos outros) }\end{array}$ \\
\hline $\begin{array}{l}\text { Exemplo - no enunciado: } \\
\text { Temos o aspecto: }\end{array}$ & \multicolumn{1}{c|}{$\begin{array}{c}\text { Eedro foi prudente. } \\
\text { PERIGO PORTANTO PRECAUÇÃO oncadeamento: }\end{array}$} \\
\hline
\end{tabular}

Fonte: elaboração do autor com base em Carel (2011).

\section{O bloco semântico: a relação suporte, conector, aporte e negação}

Queremos chamar a atenção para a seguinte particularidade: ora, só se transgride se, primeiramente, houve uma concordância. Por exemplo, a transgressão de desvirtuoso [DEVE FAZER NO ENTANTO NEG-FAZ] só existe e só significa porque primeiro existe e significa sua normatividade, $o$ virtuoso [DEVE FAZER PORTANTO FAZ] (CAREL; DUCROT, 2005, p. 67). Como explicar bem "algo que não é" (desvirtuoso) senão a partir do que "se afirma que é" (virtuoso)? Queremos dizer que, de alguma forma, semanticamente, a negação conclama a afirmação. Não há como discordar senão a partir do que não se concorda (se se discorda, se discorda do quê?). A discordância é sempre o segundo gesto diante de um primeiro gesto, a concordância. Assim, toda discordância revela uma concordância, ou, 
tecnicamente, toda transgressividade (aspecto segundo) revela uma normatividade (aspecto primeiro).

Fiel a uma das ideias chaves da Semântica Argumentativa, de que a negação pressupõe a afirmação, observamos na TBS que existe uma relação de singularidade, mesmo entre as dinâmicas do tipo "portanto" e "no entanto". Há uma ideia única que as relaciona. Este "algo em comum", na relação norma/ transgressão de certa expressão, enunciado ou discurso, é chamado por Ducrot de "representação semântica única" (DUCROT, 2009, p. 22), mas conhecida, segundo a terminologia da TBS, como um bloco semântico.

No exemplo supracitado, quando o motorista contraria sua carona, ao contraenunciar um "depressa demais no entanto não correr o risco de acidentes", ele só o faz diante da advertência "depressa demais portanto correr o risco de sofrer acidente". Temos, assim, na relação entre a negação/afirmação, o bloco semântico de: [depressa demais CONN risco de sofrer acidente].

Carel ainda vai ampliar esta máxima - de que a negação pressupõe afirmação - apresentando mais três movimentos. Isto é, para a linguista, um bloco semântico desdobra-se em quatro faces, assim: pensando o aspecto do mau condutor, o imprudente [depressa demais PORTANTO risco de sofrer acidente]; ainda pode-se desdobrar essa ideia central em mais outras três, assim: existe ainda a ideia do condutor de manobras radicais, auda- cioso, o excelente condutor, que mesmo estando depressa demais, diria que não apresenta risco algum na direção devido à sua habilidade de alto nível [depressa demais NO ENTANTO NEG- risco de sofrer acidente]; e, se excelente, também há o péssimo condutor, a significação de "barbeiro", que seria aquele que, mesmo em situação de baixa velocidade, apresentaria riscos de acidente [NEG-depressa demais NO ENTANTO risco de sofrer acidente], seriam as pessoas com extrema dificuldade para dirigir, em qualquer situação; finalmente, ainda é possível pensar, neste bloco semântico (péssimo, excelente e mau condutor), a ideia do bom condutor, que lhe completaria. Ele seria aquele que corresponde à significação do senso comum de prudente na direção, de que um bom motorista evita o excesso de velocidade, e por isso anda bem e não corre risco algum de acidente [NEG-depressa demais PORTANTO NEG- risco de sofrer acidente].

Perceba-se, então, que o bloco semântico se constitui por quatro pontos, que se articulam semanticamente, e constituídos ao se mudar a negação do suporte ou do aporte, e ao mudar os conectores (portanto e no entanto) entre o suporte e aporte, das duas palavras chaves do bloco. Em suma, a TBS permite pensar quatro possibilidades de significar a relação entre depressa e risco de acidente (CAREL, 2011, p. 67). Vejamos o Quadro 2: 
Quadro 2 - O bloco semântico

Bloco semântico de: [depressa demais CONN risco de sofrer acidente]

\begin{tabular}{|c|c|}
\hline Aspectos & $\begin{array}{c}\text { Expressão } \\
\text { correspondente }\end{array}$ \\
\hline $\begin{array}{l}\text { [depressa demais POR- } \\
\text { TANTO risco de sofrer } \\
\text { acidente] }\end{array}$ & $\begin{array}{l}\text { mau condutor } \\
\text { (ou imprudente) }\end{array}$ \\
\hline $\begin{array}{l}\text { [depressa demais NO } \\
\text { ENTANTO NEG- risco de } \\
\text { sofrer acidente] }\end{array}$ & $\begin{array}{l}\text { excelente condutor } \\
\text { (ou de manobras } \\
\text { radicais) }\end{array}$ \\
\hline $\begin{array}{l}\text { [NEG-depressa demais NO } \\
\text { ENTANTO risco de sofrer } \\
\text { acidente] }\end{array}$ & $\begin{array}{l}\text { péssimo condutor } \\
\text { (ou barbeiro) }\end{array}$ \\
\hline $\begin{array}{l}\text { [NEG-depressa demais } \\
\text { PORTANTO NEG- risco de } \\
\text { sofrer acidente] }\end{array}$ & $\begin{array}{l}\text { bom condutor } \\
\text { (ou prudente) }\end{array}$ \\
\hline
\end{tabular}

Fonte: elaboração do autor com base em Ducrot (2009, p. 22).

Voltemos a considerar a evolução significante da escala argumentativa (péssimo - mau - bom - excelente), mas agora com o refinamento grupal de um único bloco semântico, ao observar que os aspectos citados se concretizam pelos seguintes encadeamentos:

O excelente condutor conduz depressa demais, no entanto, não corre o risco de sofrer um acidente.

O bom condutor não conduz depressa demais, portanto, não corre o risco de sofrer um acidente.

O mau condutor conduz depressa demais, portanto, corre o risco de sofrer um acidente.

O péssimo condutor não conduz depressa demais, no entanto, corre o risco de sofrer um acidente.
Portanto, a TBS é uma teoria semântica de metodologia ampliativa: hipoteticamente, qualquer palavra ou expressão apresenta um único bloco semântico, que se desdobra em outros pontos semânticos.

Assumir esses quatro movimentos da relação suporte/aporte, combinados entre conexões e negações, significa dizer que se preservam as posições de suporte e aporte, mas não se preservam suas interações no bloco. A interdependência entre aporte e suporte não significa que eles não possam ser articuláveis através dos conectores e negações, que acabam entrando no jogo da interdependência entre seus termos. A significação é tangenciável em um bloco, isto é, a significação pode transformar-se a depender do conector e da negação no aporte e/ ou suporte, mas se preserva a "ideia semântica" de um único bloco.

Temos aqui a tão esperada representação semântica única, almejada por Ducrot, o bloco semântico: a interdependência entre dois termos [suporte+aporte] que se combinam em quatro possibilidades (iniciais), a partir dos conectores (portanto e no entanto), e da negação NEG, operáveis por relações fora de uso da língua (frase) ou de uso da língua (enunciação). Por exemplo, a expressão citada de excelente condutor possibilita a inter-relação entre as três expressões: péssimo condutor, mau condutor e bom condutor.

Eis o refinamento: uma teoria que vislumbra a disposição de uma significação em relação a outras três é na verdade uma 
teoria que dá a sofisticação de uma perspectiva expansiva à investigação semântica, já que nunca termina nela mesma, e vinga a tese de Ducrot de que é possível uma relação grupal entre estruturas distintas com representação semântica única: o bloco semântico (DUCROT, 1990).

\section{O quadrado argumentativo: a relação aspecto/aspecto}

Para fins de notação teórica, os dois conectores (CONN) bases da TBS são abreviáveis por:

DC (donc do francês) - que significa PORTANTO; e

$\mathrm{PT}$ (pourtant do francês) - que significa NO ENTANTO.

Deste modo, para operar as análises, manteremos as abreviações DC para movimentos normativos em portanto e PT para movimentos transgressivos em no entanto. Outras notações necessárias são a já conhecida negação (NEG) e o bloco semântico (BS).

Ainda é relevante frisar que ambos, DC e PT, são conectores metalinguísticos, noções teóricas, isto é, não se equivalem a procedimentos gramaticais, são conectores técnicos cuja função é operar semanticamente a norma e a transgressão na língua e na enunciação, no sentido que lhes dá a TBS. E, como noção técnica, tanto DC como PT podem facilmente ser substituídos por qualquer conector que carregue a mesma ideia equivalente, como "então, porque, logo, assim, apesar de, porém, contudo, etc.", que, no momento de análise, tornar-se-ão paráfrases de DC ou PT. Vejamos o quadrado argumentativo apresentado na Figura 1:

Figura 1 - O quadrado argumentativo de: [depressa demais CONN risco de sofrer acidente]
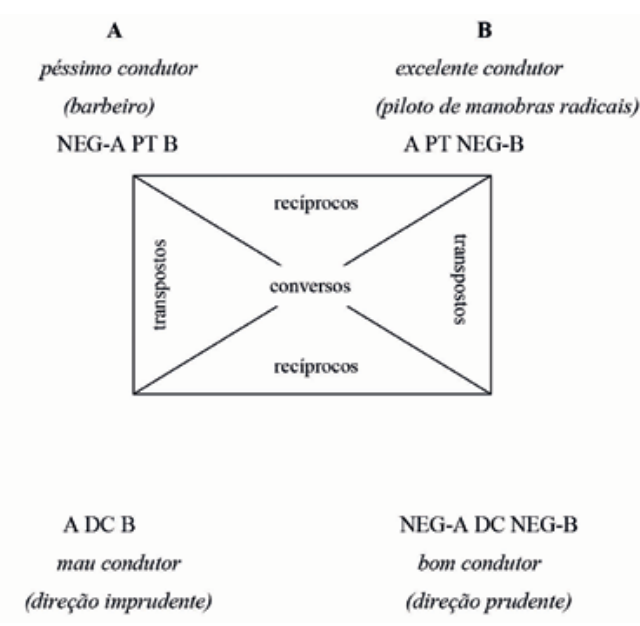

Fonte: elaboração do autor com base em Ducrot (2009, p. 22) e Carel (2011, p. 67).

Podemos explorar três relações possíveis entre seus quatro aspectos. Classicamente, os alcances do quadrado argumentativo são pensados em três particularidades entre aspectos de um mesmo bloco semântico: as relações conversa, transposta e recíproca.

Pensadas aos pares, e de modo sucinto - por não ser o alvo deste artigo -, as relações conversas significam, no mínimo, transgressões; as transpostas significam, no mínimo, intensificações; e as recíprocas significam, no mínimo, transgressões fortes. Essas relações, evidentemente, foram trabalhadas nos 
últimos 25 anos de TBS, e recomenda-se trabalhos atuais de Carel e Ducrot nessa linha, para um melhor aprofundamento dessas três relações clássicas.

\section{Análise do corpus: o problema teórico do paradoxo do morto-vivo}

Um paradoxo desafia qualquer engendramento teórico e exige procedimentos engenhosos de observação para um semanticista, ao mesmo tempo que põe à prova trabalhos em Semântica. $\mathrm{E}$, por isso mesmo, o paradoxo não deve ser evitado, como ensinou a tradição da Lógica. Se o semanticista for exigente, ele é o critério de evolução e sofisticação de teorias semânticas. Vejamos como a TBS se porta diante de um paradoxo.

Vamos iniciar a explicitação de nosso problema. Vamos pensar a significação do morto-vivo. O sentido paradoxal de "um cadáver com vida", ou, tecnicamente, o sentido interdependente de [um-morto-que-de-alguma-forma-está-vivo], leva o semanticista a pensar, inicialmente, nos limites das significações das palavras "morto" e "vivo", mobilizando o seguinte critério: filosoficamente, como a morte afeta a vida, e como a vida afeta a morte?; semanticamente, em que medida a vida pode estar significada na morte $\mathrm{e}$ a morte pode estar significada na vida? Se o fizermos pelo método supracitado do bloco semântico, procedimentalmente, vamos, a princípio, considerar a relação entre estas duas palavras, "morto" e "vivo", nos seus quatro aspectos iniciais:

- podemos falar de alguém que, de fato, está morto biologicamente e por isso não apresenta sinais vitais. É a significação da palavra "óbito", por exemplo.

- Usaremos a expressão morte total: [MORTO PORTANTO NEG-VIVO];

- podemos falar de alguém que apresenta mortalidade, mas que, de alguma forma, apresenta sinais vitais, como a "morte encefálica", na qual se constata óbito neurológico, mas os órgãos apresentam sinais vitais. Pode ser, por exemplo, o "infarto do miocárdio", que é a morte de uma região do músculo cardíaco causada pela obstrução de sangue abrupta.

- Usaremos a expressão morte parcial: [MORTO NO ENTANTO VIVO];

- podemos falar de casos - não raros - em que "alguém vivo" se comporta "como morto", isto é, não se pode afirmar que está morto, porque está vivo, mas também não se pode afirmar que vive, porque se comporta friamente, porque suas emoções estão como mortas. Significação própria de ditados paradoxais como: "morreu e esqueceu-se de cair". Ou ainda da expressão "morte psicossocial", ou ainda de expressões como "indiferente". Outro exemplo, não biológico, seria a significação própria da palavra "desaparecimento" ou da expressão jurídica "morte presumida", já que com um desaparecimento e com a falta de um cadáver não se pode afirmar a morte (neg-morte) nem se pode afirmar a vida (neg-vida). 
- Usaremos morte emocional: [NEG-MORTO NO ENTANTO NEG-VIVO];

- podemos falar, ainda, na obviedade do senso comum, de alguém que não está morto, e por isso mesmo está vivo.

- Usaremos a expressão vida total: [NEG-MORTO PORTANTO VIVO].

Podemos observar as quatro faces do mesmo bloco semântico no Quadro 3:

Quadro 3 - Bloco semântico de: [morto CONN vivo]

\begin{tabular}{|l|l|l|}
\hline \multicolumn{1}{|c|}{ Encadeamento } & \multicolumn{1}{|c|}{ Aspecto } & Expressão \\
\hline $\begin{array}{l}\text { João está totalmente } \\
\text { morto, portanto não } \\
\text { apresenta sinais vitais. }\end{array}$ & $\begin{array}{l}\text { [MORTO } \\
\text { PORTANTO } \\
\text { NEG-VIVO] }\end{array}$ & $\begin{array}{l}\text { morte total } \\
\text { (óbito) }\end{array}$ \\
\hline $\begin{array}{l}\text { João apresenta morte de } \\
\text { órgãos importantes, no } \\
\text { entanto ainda há algu- } \\
\text { mas funções vitais. }\end{array}$ & $\begin{array}{l}\text { ENTANTO } \\
\text { VIVO] }\end{array}$ & morte \\
\hline $\begin{array}{l}\text { João não está morto, } \\
\text { no entanto comporta-se } \\
\text { como se não estivesse } \\
\text { vivo. }\end{array}$ & $\begin{array}{l}\text { [NEG-MORTO } \\
\text { NONTANTO } \\
\text { NEG-VIVO] }\end{array}$ & morte \\
\hline $\begin{array}{l}\text { João não está morto, } \\
\text { portanto está vivo. }\end{array}$ & $\begin{array}{l}\text { [NEG-MORTO } \\
\text { PORTANTO } \\
\text { VIVO] }\end{array}$ & vida total \\
\hline
\end{tabular}

Fonte: elaboração do autor.

Logo, com o refinamento grupal de um único bloco semântico (as significâncias entre "morto-vivo"), observa-se que os aspectos desse bloco se concretizam pelos encadeamentos, como os exemplificados anteriormente (Figura 2).
Figura 2 - O quadrado argumentativo da "vida biológica" humana: [morto CONN vivo]

$\begin{array}{lc}\text { (deprimido, indiferente, etc.) } & \text { (morte encefálica, etc.) } \\ \text { morte emocional } & \text { morte parcial } \\ \text { NEG-morto PT NEG-vivo } & \text { morto PT vivo }\end{array}$

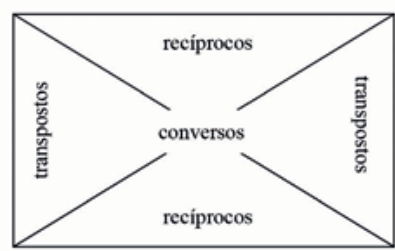

$\begin{array}{ll}\text { morto DC NEG-vivo } & \text { NEG-morto DC vivo } \\ \text { morte total } & \text { vida total } \\ \text { (óbito) } & \text { (saíde) }\end{array}$

Fonte: elaboração do autor.

Note-se, contudo, e isso é crucial, que ainda assim as quatro faces desse bloco semântico não são suficientes para descrever a significação de morto-vivo, expressão que também apresenta os semantismos morto e vivo, interdependentes, não se o quisermos fazer pelo bloco supracitado (seria fácil "apelar" para outros blocos, que expressassem, por exemplo, "morto-vivo portanto...". Mas acredita-se não ser um procedimento exigente se o objetivo for flagrar o valor de morto-vivo, que obrigatoriamente passa pelas significâncias de morto e de vivo).

Pode-se, a princípio, pensar ser razoável descrever o morto-vivo pelo aspecto duvidoso de "morte emocional" [NEG-MORTO NO ENTANTO NEG-VIVO]. O que não procede, já que um morto-vivo é algo além de uma dúvida. 
Não temos dúvida sobre sua morte ou sobre sua vida: ela está morta e está viva (tecnicamente, ao invés dos elementos negativos: neg-morte e neg-vida, têm-se os elementos afirmativos: morte e vida). Essa refinada diferença aclarar-se-á ao seu tempo.

Por ora, convém ponderar que a citação não se trata de "a criatura pode não estar morta, no entanto pode não estar viva" (porque é um cadáver, está morto, e foi lhe dado vida, está vivo); nem se trata de transgredir a vida: "a criatura não está morta, mas não está viva” (porque está morta e, apesar disso, mostra sinais de vida, e essa combinação produz o efeito de horror enunciado pelo doutor).

A nossa exigência e acuidade para com a significação nos fará afirmar que o morto-vivo de Shelley não adentra esses quatro aspectos, porque um morto-vivo não transgride a morte para mostrar-se vivo, nem transgride a vida para mostrar-se morto. Um morto-vivo é significado na estranheza paradoxal de "a criatura está morta e está viva" (marca-se bem o "e"). Ele está vivo e está morto, interdependentemente. Elemento que ainda não está nos quatro aspectos clássicos da TBS. É essa estranheza a significação de morto-vivo. O semanticista deve ser exigente: a significação de morto-vivo não se trata de dúvida entre vida e morte, nem da abstração de possíveis vidas e mortes (interpretações outras). Não se trata de transgressão da morte (por exemplo, "ressurreição", já que esta significação prevê a passagem da morte para a vida, excluindo-se a morte, e morto-vivo está ressurrecto, mas ainda morto), nem de transgressão da vida (por exemplo, a passagem da vida para a morte, já que, mesmo cadáver, mostra-se vivo). Trata-se antes de união dos contrários: vida-e-morte. Trata-se de um paradoxo, portanto. Enfim, semanticamente, adotaremos a exigência de não analisar a expressão morto-vivo separadamente.

Teoricamente, para explicar a significação "morto-vivo", seria necessário um procedimento que coadunasse "morto-e-vivo", de modo interdependente, e que saísse dos lugares engessados em que se pode enxergar um estado isolado de morto e um estado isolado de vivo, mas considerando a estranheza desses dois lugares sem possibilidade de seccioná-los, de modo que não é mais possível discernir predominância de morto ou predominância de vivo. Tecnicamente, semanticizar o paradoxo significa perscrutar lugares semânticos do limite em pleno processo não identificável, mas que identifica.

Assim, o bloco apresentado claramente não dá conta do paradoxo de morto-vivo, e por isso outras composições e movimentos teóricos serão necessários para tal. O procedimento analítico da palavra morto-vivo, por isso, será retomado adiante, auxiliado pela nova acepção teórica do quase-bloco. 


\section{O quase-bloco: a relação intermediária}

A noção de quase-bloco é a sugestão de uma manobra sofisticada para trabalhar os limites do sentido, porque trabalha justamente esta espessura semântica: o limite, que os autores preferem tratar por a alternativa (CAREL; DUCROT, 2016, p. 18). O quase-bloco é uma alternativa entre dois aspectos, o quase-bloco é a significação de uma alternativa, e não de um aspecto. É um refinamento inédito de tentativa de formalização dos limites significantes no Estruturalismo Enunciativo. Através de uma postura de formalização do limite, do entremeio, da alternativa, investiga a face oscilante da significação/sentido (que se alterna entre um aspecto e outro, significando os dois, na verdade).

Contudo, apesar da concepção inovadora, tratam-se dos primeiros momentos teóricos, o quase-bloco é uma manobra inicial, tímida, ainda por se desenvolver. Carece, portanto, de acervo de análises e consequentes publicações.

A ideia central do quase-bloco deu-se quando Carel e Ducrot perceberam que há certas palavras cuja significação ou sentido são expressos pela alternativa conjunta de dois aspectos, do modo normativo (DC) e transgressivo (PT). Vejamos como Carel explica a nova concepção de quase-bloco da clássica palavra prudente:
Retomemos o eterno exemplo de "prudente": sua argumentação interna continha PERIGO DC PRECAUÇÃO, e sua argumentação externa continha os dois aspectos conversos PRUDENTE DC SEGURANÇA e PRUDENTE PT NEG-SEGURANÇA. Nós mantemos a hipótese cuja significação de 'prudente' contém o aspecto PERIGO DC PRECAUÇÃO. Ao contrário, nós dizemos agora que ele não contém nenhum dos dois aspectos PRUDENTE DC SEGURANÇA e PRUDENTE PT NEG-SEGURANÇA. O que ele comporta, é a alternativa destes dois aspectos, e não estes dois aspectos (CAREL; MACHADO, 2016, p. 5, grifo nosso).

Essa nova ideia de que uma palavra comporta "a alternativa dos dois aspectos, e não um dos dois aspectos" é mais visível em discursos polêmicos, como no exemplo:

Recebi uma boa quantia de dinheiro este mês.

Esse enunciado pode ser encadeado com o segmento "portanto vou gastar" (vou pagar contas ou fazer compra) ou com o segmento "no entanto não vou gastar" (vou por na poupança). Pela percepção nova, a significação da palavra plena dinheiro expressaria então um quase-bloco, algo como: [DINHEIRO DC GASTAR e DINHEIRO PT NEG-GASTAR].

Até então, essa possibilidade não existia na TBS, e o semanticista deveria efetivar sua interpretação em uma das duas direções: ou normativa, ou transgressiva (a não ser que o analista construísse um bloco com "gastar e não gastar" em um único aspecto, o que está autorizado teoricamente, mas poderia parecer muito estranho semanticamente). Agora, o 
conteúdo intermediário ganha interesse na Semântica Argumentativa e adentra a teoria por meio do conceito técnico de quase-bloco, que prevê não mais a exatidão [X DC Y] ou [X PT NEG-Y], mas o entremeio da alternativa [X DC Y + X PT NEG-Y] para descrever as significâncias na língua.

Nesse caso, não importa muito a situação: alguém que tenha dinheiro, endividado ou não, rico ou não, precisando ou não, bom administrador ou mau administrador, consequente ou inconsequente, etc., pode compreender dinheiro na alternativa de duas direções argumentativas: ter dinheiro significa a soma de duas alternativas argumentativas: gastá-lo "e" guardá-lo (e não a escolha: gastá-lo "ou" guardá-lo). A alternativa semântica de dinheiro é: [DINHEIRO DC GASTAR + DINHEIRO PT NEG-GASTAR]. O quase-bloco trabalha com a englobante "e", e não com a excludente "ou". "Gastar" ou "guardar", isoladamente, ilustraria outros aspectos, mais particulares, como "consumidor" (o que gasta) ou "econômico" (o que não gasta), enquanto que "gastar e guardar" significam, em conjunto, ter recursos, ter crédito, ter dinheiro, etc. Também, em outras palavras, ter dinheiro (poder gastar $e$ não gastar) ilustra duas significações: ser consumidor (gastar) $e$ ser econômico (não gastar), quase-bloco que ilustra a utopia do mundo capitalista neoliberal moderno.

É justamente dessa manobra, rapidamente microanalisada neste texto, distante de aprofundamentos, que se pretende tratar a noção de quase-bloco: aspectos que vislumbram a simultaneidade do eixo de limite $\mathrm{DC}+\mathrm{PT}$, e não a decisão exata entre eles.

Epistemologicamente, o quase-bloco significa a inserção da polêmica semântica do intermediário significante no Estruturalismo Enunciativo. E a que custas teóricas? Da ressignificação desse estruturalismo para uma disposição moderna, que se interessa por uma semântica fluída, uma semântica líquida (BAUMAN, 2000), pode-se dizer. Seu desafio será perscrutar a dificuldade indecisa do quase, porque quer flagrar um "quase"-bloco na linguagem.

Embora a noção ainda seja juvenil e experimental, por jogar com o intermediário da alternativa, cremos que sua concepção é fundamental para o tratamento do paradoxo, que é um objeto de limite. E isso justifica a razoabilidade de nossa postura ao tentar refletir o quase-bloco ou, metodologicamente falando, investigar o paradoxo pelo aparato do quase-bloco.

A questão teórica que se coloca de imediato, diante da reorganização da teoria argumentativa, é: quais combinações em pares o quase-bloco pode provocar nos quatro aspectos do quadrado argumentativo? Carel e Ducrot observam dois tipos de combinações em pares: quase-blocos conversos e quase-blocos transpostos. Neste texto, serão propostos outros tipos de quase-blocos. 


\section{Quase-bloco converso: a relação [A DC C e A PT NEG-C] ou [A (C)]}

Para explicar o quase-bloco converso, Carel e Ducrot partem de um bloco estrutural observável em enunciados da carta de Jacques Rivière à Alain-Fournier, de 18 de agosto de 1905 (CAREL; DUCROT, 2014a, p. 6):

Você apresenta uma queda pelo sentimentalismo.

Você se emociona um pouco demais por detalhes que nem sempre valem a pena.

Segundo os autores, o sentimentalismo "exagerado" exprime o bloco estrutural ilustrado na Figura 3.

Figura 3 - Bloco estrutural de [TRISTEZA CONN EMOCIONADO]

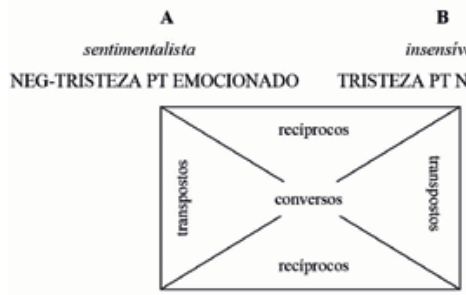

$\begin{array}{cc}\text { sensivel } & \text { racional } \\ \text { TRISTEZA DC EMOCIONADO } & \text { NEG-TRISTEZA DC NEG-EMOCIONADO }\end{array}$

Fonte: Carel e Ducrot (2014a, p. 6, tradução nossa).

Contudo, Carel e Ducrot chamam a atenção para a relação existente entre tal bloco estrutural e um outro contex- tual (também chamado de bloco de ocorrência). Falemos desse bloco contextual. Consideremos a ocorrência de expressões como medíocre no enunciado:

A história do vigia que você me contou é boa, mas - como direi eu - um pouco medíocre (CAREL; DUCROT, 2014a, p. 6).

Que evocaria o seguinte encadeamento:

A história do vigia é medíocre, no entanto, você se emociona.

Carel e Ducrot lembram que pode haver ainda um outro enunciado interessante nessa relação, como: "Você, Alain, se emociona fácil, mas eu, Jacques, não", a partir da evocação de encadeamentos como: "A história do vigia é medíocre, portanto eu não me emociono".

Nessa observação, os autores fazem notar que temos duas alternativas de aspectos para a palavra medíocre, contextualmente, na ocorrência de história medíocre: uma passível de se emocionar (caso do interlocutor Alain), como [NEG-TRISTEZA PT EMOCIONADO], e outra não passível de se emocionar (caso do locutor Jacques), como seu converso [NEG-TRISTEZA DC NEG-EMOCIONADO], ambas observáveis no bloco apresentado. O sentido de história mediocre, conforme os enunciados supracitados (contextualmente), é emocionar-se e não se emocionar, diante de algo que não é triste (frisa-se o "e", que não é "ou"). É a alternativa desses dois aspectos.

Tecnicamente, temos aí um quase-bloco converso, que os autores notam da seguinte forma: NEG-TRISTEZA 
(EMOCIONADO), em que os parênteses significam a soma da afirmação e a ne- gação do aporte "emocionado", isto é, a soma dos conversos do bloco. Deste modo:

\section{[NEG-TRISTEZA PT EMOCIONADO + NEG-TRISTEZA DC NEG-EMOCIONADO] = o quase-bloco de história mediocre: [NEG-TRISTEZA (EMOCIONADO)]}

Vejamos o quase-bloco contextual de história mediocre no quadrado argumentativo, que soma os conversos do quadrado estrutural apresentado (CAREL; DUCROT, 2014a, p. 7), conforme a Figura 4:

Figura 4 - O quase-bloco contextual de história medíocre

história mediocre (atribuido ao interlocutor Alain-Fournier) NEG-TRISTEZA PT EMOCIONADO

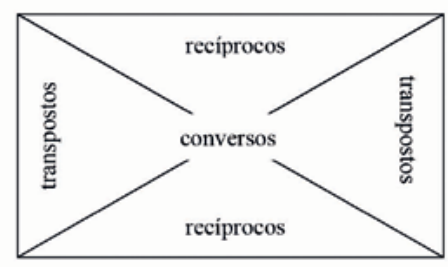

NEG-TRISTEZA DC NEG-EMOCIONADO

história mediocre (atribuido ao locutor Jacques Rivière)

Fonte: elaboração do autor com base em Carel e Ducrot (2014a, p. 7).

Como observado na Figura 4, este procedimento de análise semântica, para flagrar "algo como" a possibilidade da alternância entre dois aspectos, é chamado por Carel e Ducrot de quase-bloco, uma noção não linear, não estabilizada para tratar as significâncias:
A expressão tipo 'medíocre' não é ambígua. A significação linguística de 'medíocre' não contém os dois aspectos [NEG-TRISTEZA DC NEG-EMOCIONADO] e [NEG-TRISTEZA PT EMOCIONADO]: ela contém a alternativa destes dois aspectos, a qual nós chamaremos o 'quase-bloco' de seus dois aspectos. Certas ocorrências de 'medíocre' tem por sentido [NEG-TRISTEZA DC NEG-EMOCIONADO] e certas ocorrências de medíocre tem por sentido [NEG-TRISTEZA PT EMOCIONADO] (CAREL; DUCROT, 2014a, p. 7).

Podemos ainda explorar/aprofundar a questão do quase-bloco pela polifonia, construto teórico caro à TBS e consagrado em pesquisas semânticas. Do modo como Carel e Ducrot colocaram a questão supracitada, a significação/sentido do quase-bloco de medíocre se constrói polifonicamente, isto é, estabelece-se contextualmente entre um EU e um $\mathrm{TU}$, entre um locutor e um interlocutor: a Alain é atribuída uma inclinação à sensibilidade, e Jacques afirma sua pertença à não sensibilidade, no que tange à significância do termo medíocre. Mas Carel e Ducrot ainda vão explorar a possiblidade de um ELE neste jogo de quase, propondo outro enunciado para robustecer a análise: 
Maria e Pedro acabaram de se sentar quando iniciou o filme. Tratava-se de uma história assustadoramente dramática, tal como Bambi, na qual a mãe se sacrifica. Era de fato mediocre: ele choraria? (CAREL; DUCROT, 2014a, p. 7).

A significância do ELE se constrói pelo sentido da dúvida, marcada pela indagação em interrogação: ele choraria? Sobre esses enunciados, Carel e Ducrot afirmam que o sentido de "medíocre", ali, é um quase-bloco de duas possibilidades, postas pela dúvida do pranto diante da história medíocre: "[...] a ocorrência de 'medíocre' em 'Era de fato mediocre: ele choraria?' tem por sentido o quase-bloco converso acima; pois nós nos perguntamos se Pedro vai ou não se emocionar" (CAREL; DUCROT, 2014a, p. 7). E na impossibilidade de uma resposta escolhida (que não interessa à análise semântica dos enunciados, justamente porque não há indícios dessa escolha), o sentido de história medíocre se produz pela soma da alternativa de se emocionar e não diante da história medíocre. Ele choraria? pressupõe poder chorar e não chorar.

\section{Quase-bloco transposto: a relação [NEG-A PT C e $\mathrm{A}$ DC C] ou [(A) C]}

Vimos anteriormente a exposição do quase-bloco em relações conversas do quadrado argumentativo. Carel e Ducrot mostram que também é possível observar o fenômeno do quase-bloco na língua no formato transposto do quadrado, a partir da expressão tipo (ou estrutural) chorar:
[...] certas ocorrências da expressão tipo 'chorar' têm por sentido [TRISTEZA DC EMOCIONAR] (O tempo de aprender a viver já está muito tarde. Que chorem na noite os nossos corações em uníssono. Aragon); outras ocorrências têm por sentido [NEG-TRISTEZA PT EMOCIONAR] (Então, você assistiu 'Jogos proibidos'? Você gostou? - Sem problemas. Como você pôde chorar?). A expressão tipo 'chorar' não é ambígua; sua significação contém a alternativa de seus dois aspectos, seu quase-bloco (CAREL; DUCROT, 2014a, p. 7).

Que será conforme o exposto na Figura 5:

Figura 5 - O quase-bloco de chorar

Chorar (expresso na apreciação de um filme) NEG-TRISTEZA PT EMOCIONAR

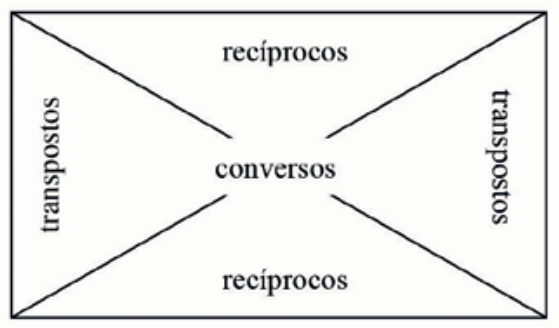

Chorar (expresso no verso de Aragon)

TRISTEZA DC EMOCIONAR

Fonte: elaboração do autor com base em Carel e Ducrot (2014a, p. 7).

A notação desse quase-bloco transposto será: "(TRISTEZA) EMOCIONAR", como no exemplo anterior, em que os parênteses significam a alternativa simultânea de afirmação/negação na palavra. Assim: 
Existe uma diferença básica nos dois exemplos (mediocre e chorar): na análise de mediocre, vimos que os enunciados que envolviam a análise integravam um mesmo discurso - o EU-locutor (Jacques) e o TU-interlocutor (Alain) - compunham as duas alternativas do quase-bloco de medíocre. Já no exemplo de chorar, os autores dão exemplos de ocorrências distintas a partir de discursos distintos, intertextuais (discurso de Aragon e discurso de um filme, "Jogos Proibidos"). Assim, não importa se, no mesmo discurso ou não, a noção de quase-bloco pode ilustrar a soma de duas possibilidades opostas (triste e não triste, emocionar e não se emocionar, etc.) observáveis no léxico de uma palavra plena.

Em suma, a notação técnica de quase-bloco, sugerida pelos autores (CAREL; DUCROT, 2014a, p. 9), será:

I) Quase-bloco converso [A DC C e A PT NEG-C] notado por: "A (C)";

II) Quase-bloco transposto [NEG-A PT C e ADC C] notado por “(A) C”.

Em que A representa o suporte e $\mathrm{C}$ o aporte, e os parênteses representam $o$ segmento sobre o qual recai a afirmação + a negação, própria do quase-bloco.
Carel e Ducrot enfatizam a natureza intermediária, de entremeio, da noção de quase-bloco, necessária para aprofundar a investigação dos limites significantes/ significáveis na Semântica Argumentativa: "Um quase-bloco é uma unidade argumentativa intermediária entre $o$ aspecto argumentativo e o bloco semântico. Existem dois tipos de quase-blocos, os quase-blocos de conversos (cf. a significação de medíocre) e os quase-blocos de transpostos (cf. a significação de chorar)" (CAREL; DUCROT, 2014a, p. 9, grifo nosso).

O quase-bloco põe em evidência duas expressões contrárias de modo não decidido, uma significância de hesitação: afinal, devo me emocionar ou não diante de algo medíocre? Afinal, seria plausível chorar ou não diante de filmes ridículos? O quase-bloco é a noção formal que marcará essa hesitação.

\section{Análise dos quase-blocos de vida biológica}

Retomemos o bloco semântico de "vida biológica" para explorar/expandir suas significâncias por meio da noção teórica de quase-bloco. Comecemos pelo procedimento do quase-bloco converso, que soma as alternativas diagonais (ditas conversas) do quadrado argumentativo (Figura 6). 
Figura 6 - O quadrado argumentativo estrutural da "vida biológica": [morto CONN vivo]

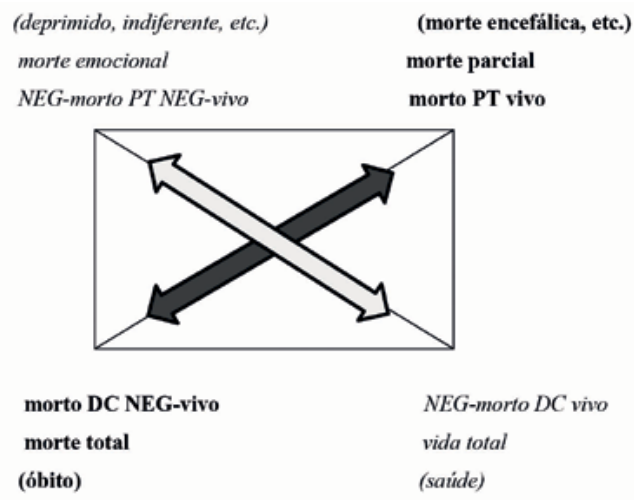

Fonte: elaboração do autor.

O par negritado, ligado pela flecha preta, representa o procedimento analítico da consideração somática de dois aspectos conversos, a saber: [MORTO (VIVO)], e o par em itálico, ligado pela flecha branca, representa o outro procedimento somático dos outros dois aspec- tos conversos, a saber: [NEG-MORTO (VIVO)]. Uma vez que, através da noção de quase-bloco, podemos pensar pares de aspectos, até opostos, mas que compõem significações de várias expressões relacionadas à vida e à morte do homem. Expliquemos um e outro.

A expressão morte (sem os adjetivos "total" e "parcial") significa cessação de atividades totais e também parciais, isto é, a morte pode significar-se integralmente (óbito: MORTO DC NEG-VIVO), sobrepondo-se à vitalidade e também convivendo com essa vitalidade, no caso de mortalidade de alguns órgãos (morte cerebral, morte pulmonar, o breve período em que alguém está reanimando um coração que cessou de bater, etc.: MORTO PT VIVO). Semanticamente, a expressão plena morte trabalha esses dizeres médicos significando a alternativa em quase-bloco dos seguintes pares de aspectos:

\section{[MORTO DC NEG-VIVO + MORTO PT VIVO] =}

\section{o quase-bloco converso de morte: [MORTO (VIVO)]}

Do mesmo modo, temos a outra linha diagonal do quadrado argumentativo, que ilustra expressões como dinâmica da vida. Deixando de lado as infindas definições de viver, para delimitar nosso quadrado argumentativo da vida biológica humana, observamos que a vida, de alguma forma, ilustra um par semântico-comportamental: mostrar-se ou agir com vitalidade e também não se mostrar ou não agir com vitalidade (considerando o critério de que viver, biologicamente, não importa qual seja a cultura ou $o$ meio social, é comportar-se de alguma forma: ativamente ou não ativamente). Mais tecnicamente, o ser humano vive ao agir/mostrar-se com vitalidade, às vezes, ou sempre (uma vida ativa, proativa, hiperativa, etc.: NEG-MORTO DC VIVO), e também, às vezes, ou sempre, ao agir/ mostrar-se sem vitalidade, como alguém que "morreu e esqueceu de cair" (vida depressiva, vida com transtorno de pânico, transtorno de ansiedade, etc.: NEG-MORTO PT NEG-VIVO). Semanticamente, a dinâmica da vida, ao longo da história, 
universalizou as significâncias das duas alternativas, que engloba a trivialidade vital (significar-se saudável pelo trabalho, afazeres, relacionamentos, lazer, etc.) somada a atravessamentos emocionais (significar-se como (in)feliz, triste, frio, deprimido, etc.), ambos visíveis na soma do par converso, em quase-bloco. Viver é engajar-se nesse processo dinâmico.

Tecnicamente, a expressão plena $d i$ nâmica da vida significa a alternativa dos pares de aspectos:

[NEG-MORTO DC VIVO + NEG-MORTO PT NEG-VIVO] = o quase-bloco converso de dinâmica da vida: [NEG-MORTO (VIVO)]

Na sequência, passemos à análise pelo procedimento do quase-bloco transposto, que soma as alternativas laterais (ditas transpostas) do quadrado argumentativo em questão, conforme a Figura 7.

Figura 7 - O quase-bloco transposto
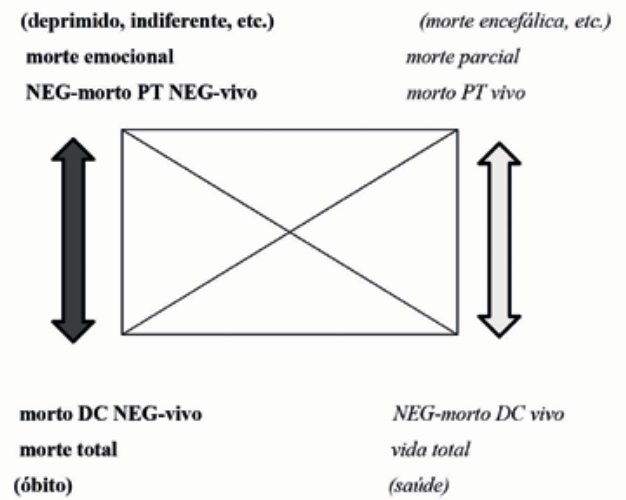

Fonte: elaboração do autor.
Na Figura 7, o par negritado, ligado pela flecha preta, representa o procedimento analítico da consideração somática de dois aspectos transpostos da esquerda, a saber: [(MORTO) NEG-VIVO], e o par em itálico, ligado pela flecha branca, representa o outro procedimento somático dos outros dois aspectos transpostos da direita, a saber: [(MORTO) VIVO]. Vejamos um e outro.

A expressão falta de vitalidade significa a soma das alternativas de dois aspectos: estar em óbito (MORTO DC NEG-VIVO) e como se estivesse em óbito (NEG-MORTO DC NEG-VIVO). Já que esta expressão, tecnicamente, ilustra a alternativa dos dois aspectos:

\section{[MORTO DC NEG-VIVO + NEG-MORTO PT NEG-VIVO] = o quase-bloco transposto de falta de vitalidade: [(MORTO) NEG-VIVO]}

Por outro lado, do lado direito do quadrado argumentativo, podemos pensar expressões como vitalidade, que, semanticamente, significa ter vida plenamente e também parcialmente. Se a falta de vitalidade ilustra a totalidade e a parcialidade do óbito, a vitalidade, por sua vez, ilustra o quase-bloco da totalidade (NEG-MORTO DC VIVO) e da parcialidade da vida (MORTO PT VIVO), tecnicamente observável em: 


\section{Complementariedade de oposição: a relação entre aspectos do quase-bloco}

Como vimos, a atualização da TBS se dá não apenas nas relações (agora tripla) entre normativo [DC], transgressivo [PT] e quase-bloco [DC + PT], mas atinge também as relações básicas: conversos, transpostos e recíprocos. A essas três os autores acrescentam uma nova relação, a de complementariedade de oposição. Isto é, por um quase-bloco converso (normativo + transgressivo), produz-se uma relação de complementariedade entre os dois aspectos que estabelecem essa oposição, agora em soma:

A conversão entre aspectos reflete a oposição: se a $\mathrm{AI}$ de um termo (corajoso) contém um certo aspecto (PERIGO PT FAZER), então, a AI da negação deste termo, pela negativa não (não corajoso), contém o aspecto converso (PERIGO DC NEG-FAZER).

A transposição reflete a gradualidade: se dois termos coordenáveis (econômico e avaro) possuem nas suas AI aspectos transpostos (NEG-ÚTIL DC NEG-COMPRAR para econômico, e ÚTIL PT NEG-COMPRAR para avaro), então, estes dois termos são religáveis por até mesmo, conforme Ele é econômico, e até mesmo avaro (a impossibilidade de 'Ele é justo, e até mesmo negligente' revela, em si, que estes dois termos não são coordenáveis).

A reciprocidade entre aspectos transgressivos pode refletir a oposição forte (conforme avaro e gastador, ou o papel de ninguém / nada... e não... jamais).

\begin{abstract}
A complementariedade entre quase-blocos, como a conversão entre aspectos, reflete a oposição: se a $\mathrm{AE}$ de um termo (chorar) contém um quase-bloco, a $\mathrm{AE}$ da negação através de não, deste termo (não chorar), contém seu quase-bloco complementar 2014a, p. 11, grifo nosso).
\end{abstract}

Converter, tecnicamente, significa ilustrar o oposto semântico de alguma normatividade, visível em um bloco. Complementarizar, tecnicamente, significa considerar esse oposto de modo semanticamente inseparável à própria normatividade, através do quase-bloco. Ambas as relações trabalham o oposto semântico, contudo, a conversão secciona e a complementariedade adiciona.

Essa atualização das relações entre aspectos é importante para refletir o quase-bloco no feitio estrutural e no feitio contextual.

\section{Quase-bloco estrutural e quase-bloco contextual}

Carel e Ducrot inscrevem as relações de complementariedade de oposição, próprias do quase-bloco, nas duas instâncias tradicionais da TBS: da frase e do enunciado, que procedimentalmente corresponde, respectivamente, aos âmbitos estrutural (que por vezes chamam de lexicalizado) e contextual: 
Um quase-bloco representa o que partilham dois aspectos, um normativo, outro transgressivo, apreendendo um mesmo bloco. Certos quase-blocos pertencem à significação de uma palavra simples da língua, como [PERIGO DC PRECAUÇÃO + PERIGO PT NEG-PRECAUÇÃO], que é significado por perigo: eles são ditos lexicalizados. Outros quase-blocos não são lexicalizados, como [PERIGO DC NEG-PRECAUÇÃO + PERIGO PT PRECAUÇÃO] ou [COMER FEIJÕES DC CONTENTE + COMER FEIJÕES PT NEG-CONTENTE] (CAREL; DUCROT, 2014a, p. 14, grifo nosso).

Nessa citação, temos um quase-bloco converso estrutural [PERIGO (PRECAUÇÃO)] e um quase-bloco converso contextual [PERIGO (PRECAUÇÃO)]. $\mathrm{E}$ o que queremos reter é que podemos falar, obviamente, em quase-blocos estruturais (ou lexicalizados) e quase-blocos contextuais.

No que diz respeito à nossa análise, o bloco semântico de vida biológica bem como seus quase-blocos são do âmbito lexical, estrutural (que ilustram significações). A partir desse bloco estrutural, em um segundo momento, podemos aprofundar/expandir a análise de tal bloco valendo-se da dimensão contextual, na sua relação com algum enunciado concreto. $\mathrm{O}$ que seria um segundo passo de análise, de blocos e quase-blocos contextuais (que produzem sentidos), que ilustrariam outros complexos de aspectos argumentativos. Por exemplo, podemos pensar no sentido produzido no choque entre o bloco de vida humana biológica - estrutural - significado no morto-vivo de Frankenstein - contextual.
A partir do bloco estrutural de vida biológica, podemos pontuar que nossa expressão privilegiadamente investigada, o morto-vivo, não possui ainda lugar semântico que lhe ilustre no bloco estrutural de vida humana biológica, se considerarmos os procedimentos até agora apresentados nesse bloco. Seu conteúdo semântico não se enquadra em nenhum dos lugares inteiriços dos quatro aspectos (morte total - porque não está em óbito; morte parcial - porque não apresenta parcialidades em óbito, ou ao menos se desconhece tal informação; morte emocional - porque não é o caso de comportamento depressivo ou semelhante; vida total - porque mesmo que não se consiga explicar, há claras diferenças semânticas entre um vivo e um morto-vivo). Tampouco a significância de morto-vivo enquadra-se nas relações clássicas (conversa, porque não se transgride a vida; transposta, porque não se intensifica ou não se atenua a morte ou a vida; recíproca, porque não se contrasta fortemente vida e morte, pelo contrário, soma-se esse contraste em morte-e-vida), e nem ainda há lugar técnico para morto-vivo nos quase-blocos já trabalhados. Não se trata da alternativa do par converso morte - porque não se trata do óbito + a parcialidade do óbito, mas da soma paradoxal óbito + saúde; nem do par converso dinâmica da vida - que em si significa o processo de vida natural, mostrando-se ou agindo com ou sem vitalidade, afastando-se da aberração de um processo bizarro de es- 
tar vivo e morto; nem do par transposto falta de vitalidade - que ilustra a soma do óbito + a morte emocional, diferente de um morto-vivo, que em si, mesmo carregando o semantismo da morte, não parece significar uma descrição comportamental, o que impossibilita determiná-lo emocionalmente; nem do par transposto vitalidade - que foge à soma vida total + morte parcial, já que o substantivo composto pleno morto-vivo apresenta igualitariamente os semantismos morte-e-vida.

Com esse arrazoado, fica claro que ainda são necessários outros movimentos para identificar a configuração semântica da expressão constitutiva morto-vivo, em um bloco semântico. O que faremos a seguir.

\section{A hipótese do quase-bloco recíproco: a relação [A DC NEG-C e NEG-A DC C] ou $[(\mathrm{A})(\mathrm{C})]$}

Nossa hipótese é que o valor semântico da expressão estrutural constitutiva morto-vivo é ilustrável se considerarmos a soma das alternativas "morte total" + "vida total", pois, estruturalmente, um morto-vivo está morto e está vivo, paradoxalmente. E a tentativa de especificar ou particularizar esta vida e esta morte é contextualizá-la de alguma forma, não trabalhando essa expressão estruturalmente. Por exemplo, pensar em mortos-vivos na contextualização de algumas séries, como Zombie Nation ou The Walking Dead, pelo caráter frio dos zumbis que ali são enunciados pelos diretores, é ilustrá-los com particularidades de sentidos de frieza, falta de lucidez, mobilização motora precária, deficiência fonadora, etc., e conversamente, significá-los pelo viés da contextualização de algumas obras, como Drácula, é ilustrá-los contrariamente aos zumbis: perspicazes, sedutores, intelectuais, detentores de oratória, etc. E, ainda, pensar pelo viés estrutural de Shelley, com base na criatura de Frankenstein, já significaria um morto-vivo ilustrável por aspectos emocionais, comportamentais, por amar seu criador e jamais ter tal amor correspondido, explicando os sentidos de maldade desse romance, dentre outros aspectos que entrelaçam a narrativa da obra produzindo a unidade textual de Frankenstein. Nenhuma dessas enunciações nos interessa, por ora, porque são contextuais. Foquemos, então, na significação estrutural de morto-vivo.

Tecnicamente, a expressão plena estrutural morto-vivo, por participar do bloco semântico de vida biológica, já que é uma configuração - mesmo que bizarra - que relaciona vida e morte, significa a soma das alternativas dos aspectos: óbito (MORTO DC NEG-VIVO) e saúde (NEG-MORTO DC VIVO):

[MORTO DC NEG-VIVO + NEG-MORTO DC VIVO] = o quase-bloco recíproco estrutural de morto-vivo: [(MORTO) (VIVO)] 
Que se vê na linha recíproca do quadrado argumentativo do bloco de vida biológica humana, ligada pela flecha preta, como pode ser observado na Figura 8:

Figura 8 - A hipótese do novo quase-bloco recíproco

$\begin{array}{ll}\text { (deprimido, indiferente, etc.) } & \text { (morte encefálica, etc.) } \\ \text { morte emocional } & \text { morte parcial } \\ \text { NEG-morto PT NEG-vivo } & \text { morto PT vivo }\end{array}$

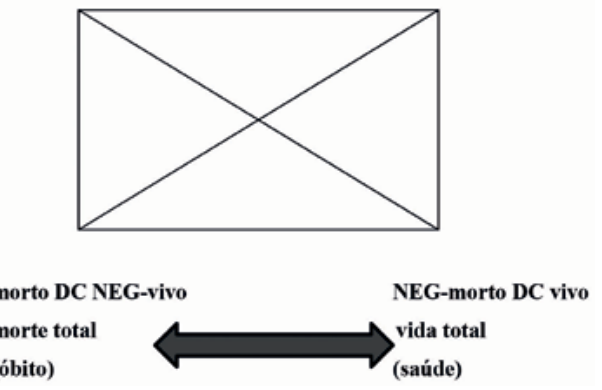

Fonte: elaboração do autor.

Outro ponto merece destaque. $\mathrm{O}$ fato de, biologicamente, esse aspecto não proceder (a existência de um morto-vivo) não o impede de, semanticamente, significar (a significação de um morto-vivo). Os objetos de estudo são diferentes em Biologia e em Semântica, já que a Semântica não é submissa a outros saberes, mas, antes, ela faz significar os outros saberes. Estamos dizendo que a possibilidade da existência é de interesse da Biologia, da Física e da Química, por exemplo, e a significação do paradoxal, fictício ou existente, não importa, é de ocupação da Semântica.

A Linguística não mantém relações de exatidão com a dimensão física do mundo. Pelo menos não na Semântica
Argumentativa. A Semântica Argumentativa não tem como critério referenciar, isto é, significar enunciações "sobre o mundo", já existente (para essa linha, significar é, prioritariamente, verificar se a linguagem relaciona-se a um mundo), mas seu critério é predicar, isto é, significar enunciações "sobre qualquer coisa”, que vão construir significações de mundos (para essa linha, significar é prioritariamente observar que a linguagem constrói [sentidos de] mundos). Assim, se linguisticamente uma anomalia é enunciável (por exemplo, morto-vivo), semanticamente ela é significável, independente de compromissos de coerência com a lógica, a razão, o ordinário, o óbvio, o doxal, o tangível, o universal, o trivial ou o social. A Semântica não é (ou não deveria ser) balizada pela linearidade ou pela coerência de qualquer tipo, porque já deixaria aí de ser Semântica (o que certa estranheza significa?) para ser estética, estilística, moral, policial, jurisprudência, cristalizações de toda ordem, etc. (o que certa estranheza "deve" significar, para não ser estranheza). Isto é, uma ciência semântica não fornece regras ou limites, fornece, antes, significações e sentidos dessas regras e desses limites. $\mathrm{E}$ se, por vezes, funciona em um ambiente acadêmico-enunciativo regrado, é apenas enquanto procedimento estratégico para se pensar essas mesmas regras que lhe constituem. Portanto, se um morto-vivo é um problema para a Biologia, para a Lógica e para a Ética, dentre tantos saberes, não o é para a Semântica. 
Em suma, frisamos que este movimento teórico, o quase-bloco recíproco, consiste em uma hipótese teórica por nós proposta, isto é, esse tipo de quase-bloco, recíproco, não foi trabalhado por Carel e Ducrot, que só apresentaram, até então, incialmente, o quase-bloco converso e o quase-bloco transposto, como visto.

\section{Palavras finais: a ressignificação da TBS a partir do quase-bloco}

A despeito da Semântica Argumentativa, a teoria se rearranja com a noção de aspecto argumentativo (duas palavras interdependentes por um conector), bloco argumentativo (com quatro aspectos argumentativos, visíveis no quadrado argumentativo) e quase-bloco (com dois aspectos, visíveis na reta transposta e conversa do quadrado argumentativo). A teoria é agora também determinada por manobras cujo alvo é o aprofundamento da imprecisão semântica:

Um quase-bloco é um esquema argumentativo menos preciso que um aspecto argumentativo (um quase-bloco pode ser apreendido de duas maneiras), e um esquema argumentativo é mais preciso que um bloco semântico (um bloco semântico pode ser apreendido de quatro maneiras) (CAREL; DUCROT, 2016, p. 18).

Mas a concepção dessa nova ideia transtornaria a dinâmica da teoria? $\mathrm{O}$ que significa mexer no cerne da TBS, transtornando seu lema de dupla instância normativa e transgressiva:
Hipótese da TBS: Todo enunciado é parafraseável por encadeamentos normativos (encadeamentos de duas proposições ligadas por uma conjunção do tipo portanto) ou transgressivo (encadeamentos de duas proposições ligadas por uma conjunção do tipo no entanto) (CAREL, 2014, p. 1).

A TBS passa, doravante, por uma revisão de tripla disposição das duas instâncias: "a significação de um termo [...] é constituída de um certo número, variável segundo os termos, de aspectos normativos, transgressivos como também quase-blocos" (CAREL; DUCROT, 2014a, p. 9). Desse modo, se a significação/sentido era observada/observável tecnicamente na TBS somente pelo(s) aspecto(s) e suas relações, agora, o quase-bloco passa a integrar a constituição da significância das palavras: "Segundo a TBS, a significação de um termo é somente constituída de aspectos argumentativos e de quase-blocos" (CAREL; DUCROT, 2014a, p. 9).

$\mathrm{E}$ o que significaria, metateoricamente, rearranjar esta hipótese de um duplo técnico para a novidade de um triplo técnico? Isto é, de $\{[\mathrm{DC}] \mathrm{e}[\mathrm{PT}]\}$ para $\{[\mathrm{DC}]$, $[\mathrm{PT}] \mathrm{e}[\mathrm{DC}+\mathrm{PT}]\}$ ? Significa entender que operar uma Semântica Argumentativa é perscrutar a riqueza da significação e do sentido nas suas dimensões contraditórias e limítrofes, por procedimentos de complementariedade de oposição, ou interdependência de alternativa semântica (normatividade + transgressão) - e isso não é inédito nessa teoria, que já se ocupava dessas problemáticas em outros tempos e ditos de outros modos, como através de noções de futuridade, 
termos retóricos, implicatura, paradoxo, ambiguidade, discurso, unidade textual, dentre outras (a maioria vista aqui, de modo sucinto), noções essas que estabeleciam relações de difícil separação entre dois ou mais pontos, a seus modos.

A significação e o significar, para essa teoria, são tais que as significâncias sempre fogem (a "fuga da significância" seria então um objeto mor da Semântica, tão ou mais importante quanto a própria "significância"), devido à materialidade fluida dos semantismos que fundam a semântica estrutural: a alternância do quase-bloco identifica significações predispostas a produzir sentidos em blocos incontáveis (e, hipoteticamente, incontroláveis, na dimensão enunciativa, que não existe sem a dimensão estrutural, ponto de início e de retorno, por mais que dela tente escapar).

A TBS, como visto neste trabalho, sempre foi sensível a questões de inesgotabilidade da significância. A TBS sempre sugere estabelecer procedimentos capazes de entrelaçar leituras de um mesmo objeto, o que significa reconhecer e querer perscrutar o fugidio objeto da significância, de riqueza imensurável e inesgotável. E a noção de quase-bloco, antes de tudo, significa assumir tal riqueza e dinâmica da significação/ sentido, que chega a "escapar do bloco", fundando outros blocos e quase-blocos, no emaranhado geométrico do arcabouço da Semântica Argumentativa.

\section{The Theory of Semantic Blocks and the intermediary significations: a study on the quasi-blocks}

\begin{abstract}
This article has as general objective to reflect on the new notion of quasi-block, proposed by Carel and Ducrot in the year 2013-2014 in Paris, France, to think border and intermediate meanings in the language. Our corpus, of theoretical and semantic nature, consists of a set of four significations originating from the expression "human biological life": death, life, partial death and emotional death. Technically said, our corpus is about the semantic block of biological life, initially composed of four main aspects. Our results point to the theoretical direction of catching the phenomenon of a semantic paradox in this corpus, given by the investigation of the term "undead", there. Technically, the four aspects of a block provide four novice relationships called quasi-transposed blocks and quasi-converted blocks, and the main result of our research is the phenomenon of a new quasi-block, called a reciprocal one. Our specific objectives are: (i) to think of the classical theoretical notions of the Theory of Semantic Blocks, initially, which will enable (ii) to better understand the theoretical development of two types of quasi-blocks proposed by the authors: Transposed quasi-block and Converse quasi-block; Finally, we aim to (iii) analyze our hypothesis: the proof of a new quasi-block not yet worked by the authors: the Mutual quasi-block, reclaimed from the problem of the undead expression, which illustrates paradoxical semantismes.
\end{abstract}

Keywords: Argumentation. Semantic blocks. Quasi-block. Paradox. 


\section{Referências}

BAUMAN, Zygmunt. Modernidade líquida. Rio de Janeiro: Zahar, 2000.

CAREL, Marion. L'entrelacement argumentatif: lexique, discours et blocs sémantiques. Paris: Honoré Champion, 2011.

Argumentation et Polyphonie: de Saint-Augustin à Robbe-Grillet. Paris : l'Harmattan, 2012.

. Tu seras un homme, mon fils. Un prologement de la doxa: le paradoxe. 2013. (Inédito).

. Argumentation et temporalité: l'exemple de quand. Inédito. 2014.

CAREL, Marion; DUCROT, Oswald. Descrição argumentativa e descrição polifônica: o caso da negação. Tradução de Leci Borges Barbisan. Letras de Hoje, Porto Alegre: PUC, v. 43, n. 1, p. 7-18, 2008.

. La semántica argumentativa: una introducción a la teoría de los bloques semánticos. Buenos Aires: Colihue, 2005.

Temporalité, Argumentation et Récit: la Théorie des Blocs Sémantiques (TBS). 2014a. (Inédito).

2016. (Inédito).

Langage poétique et discours engagé.

. Pour une analyse argumentative globale du sens. Arena Romanistica, Bergen, v. 1, p. 72-89, 2014b.

CAREL, Marion; MACHADO, Julio Cesar. Debate sobre a Teoria dos Blocos Semânticos e a Semântica do Acontecimento. Letras de Hoje, Porto Alegre, v. 51, n. 1, p. 38-46, 2016.

DUCROT, Oswald. Polifonia y Argumentación: Conferencias del seminario Teoría de la Argumentación y Análisis del Discurso. Cali: Universidad del Valle,1990.
Le dire et le dit. Paris: Les Éditions de Minuit, 1984. 